\title{
Seismic evaluation and structural design on high-rise shear wall structure
}

\author{
Youyang Xin ${ }^{\text {a }}$, Huyong Li
}

School of structural Engineering, Huanghuai University, Zhu Madian 463000, China

axinyouyang1982@163.com

Keywords: High-rise shear wall structure, Seismic evaluation, Structural design.

\begin{abstract}
This paper presents a seismic evaluation and structural design on the 160m high residential building. This high-rise shear wall structure can be determined as super high, re-entrant corners irregular and torsion irregular. Maximum value of horizontal seismic influence coefficient is 0.079 . Three different numerical models by finite element packages are established to analyze the behavior of the structure. The structure can reach the seismic design requirements.
\end{abstract}

\section{Introduction}

The No.6 building is a high-rise residential building. According to architectural functionality, the project adopts cast-in-place reinforced concrete shear wall structure form. It has 53 floors above ground and 2 floors underground. The second and first floor of the underground have a height of $4.8 \mathrm{~m}$ and $4.2 \mathrm{~m}$, respectively. The height of first floor above the ground is $4.8 \mathrm{~m}$. Height of all other floors above the ground is $3.0 \mathrm{~m}$. This project would be a landmark with a total height of the building is $160.8 \mathrm{~m}$ in the local region (Fig.1).

Project life of the structural design is 50 years. According to current code, building safety adopts grade two and seismic fortification measures adopt standard. Maximum value of horizontal seismic influence coefficient is 0.079 based on geologic survey reports. The building located in site-class 2 and its characteristic period is $0.4 \mathrm{~s}$. Wind pressure used for design chooses 0.35 which occurs once in 50 -year. Considering capacity scatter factor, the wind pressure enlarges by a 1.1 factor. Therefore, this building can be determined as super high, re-entrant corners irregular and torsion irregular when compared with various previous projects.

\section{Structure layout}

This project has a height of $160.8 \mathrm{~m}$. The plan drawing is in Fig.2. Reinforced concrete shear walls are arranged according to architectural functionality. These walls are considered as lateral force resisting system. Slabs are concreted complete. Ingenious solutions are choosen that the walls are lay along the building periphery, vertical elevator cores and other places which avoid the useage of the architecture. Those walls have a varying width of $500 \mathrm{~mm}$ to $200 \mathrm{~mm}$. And concrete grade varies from Grade 60 to Grade 40 when the floors increase. As in Fig.2, width of slab in region of elevator corewalls is smaller than other places and coreslabs display re-entrant corners irregular. Thus the slabs in the core region adopt a thickness of $150 \mathrm{~mm}$, while other slabs away from the core adopt $100 \mathrm{~mm}$.

The roof of the basement is determined as fixing place of the structure above ground in the project analysis. All loads of the structure are resisted by pile-raft foundation in which the raft thickness is $2.8 \mathrm{~m}$. Diameter of the reinforced concrete pile is $1.1 \mathrm{~m}$. Those piles can bear a characteristic value of $7800 \mathrm{kN}$ when compressing at least. The effective length of the pile reaches $30 \mathrm{~m}$ in which $10 \mathrm{~m}$ is in the bearing stratum. 


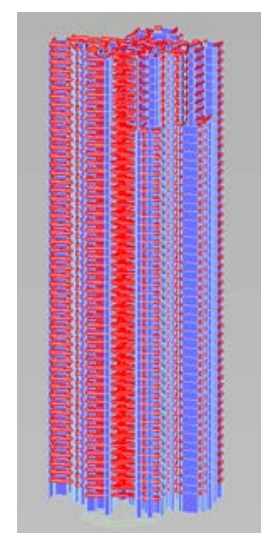

Fig.1 Plan layout

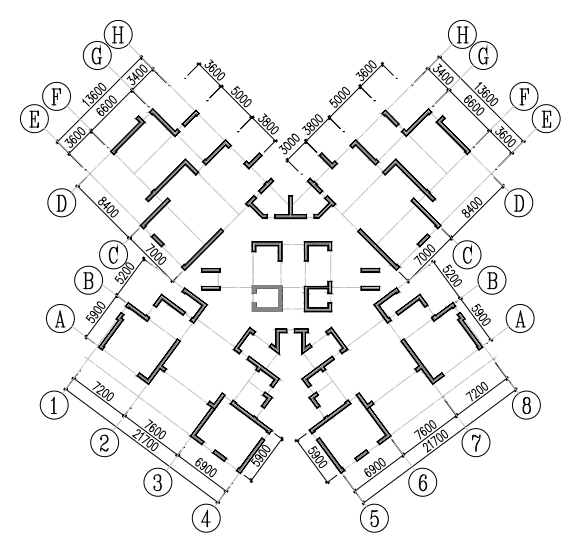

Fig.2 Plan layout

\section{Seismic design}

Seismic design of this project carries out the policy of giving priority to the prevention of earthquake disasters. Thus, the seismic fortification objective of this building should reach two levels. First, when the building is subjected to frequently earthquake influence which intensity is lower than the local fortification intensity, it will not be damaged or only slightly damaged, with continued service without repair. Secondly, when the building is subjected to rarely earthquake influence, it will not collapse nor suffer damaged that would endanger human lives. Some weak regions in the structure will be displayed during rarely earthquake analysis. Also inter-story displacement in plastic stage could be investigated and evaluated according to current design code and related design regulations.

\section{Analytical evaluation}

\subsection{Elastic analysis}

Three different numerical models by finite element packages SATWE, PMSAP and MIDAS are established to analyze the elastic behavior of the structure, according to current design codes. Results by three models are compared and verified, see Table.1. In three models, torsional effect of bidirectional horizontal earthquake action are considered in the analysis[1-3]. Comparative studies show three series of results coincide with each other very well which indicates those three models and related analysis are reliable. Seismic action along height of the building is proper arranged.

Table 1 Elastic results comparison

\begin{tabular}{|c|c|c|c|c|c|}
\hline \multicolumn{2}{|c|}{ Program } & SATWE & PMSAP & MIDAS & Limit \\
\hline \multirow{4}{*}{ Period } & $\mathrm{T} 1$ & 3.95 & 4.10 & 4.13 & \\
\hline & $\mathrm{T} 2$ & 3.84 & 3.94 & 4.04 & \\
\hline & T3 & 3.11 & 3.27 & 3.41 & \\
\hline & $\mathrm{Tt} / \mathrm{T} 1$ & 0.79 & 0.80 & 0.83 & $\leq 0.85$ \\
\hline \multirow{4}{*}{$\begin{array}{c}\text { Max inter story } \\
\text { dispt }\end{array}$} & X-earthquake & $1 / 1211$ & $1 / 1194$ & $1 / 1171$ & \multirow{4}{*}{$1 / 1000$} \\
\hline & Y-earthquake & $1 / 1303$ & $1 / 1241$ & $1 / 1194$ & \\
\hline & $\mathrm{X}$-wind & $1 / 2442$ & $1 / 2526$ & $1 / 2391$ & \\
\hline & Y-wind & $1 / 2519$ & $1 / 2633$ & $1 / 2375$ & \\
\hline \multirow{2}{*}{ Dispt ratio } & X-earthquake & 1.37 & 1.35 & 1.34 & \multirow{2}{*}{$\leq 1.4$} \\
\hline & Y-earthquake & 1.20 & 1.19 & 1.15 & \\
\hline \multirow{2}{*}{$\begin{array}{l}\text { Effective mass } \\
\text { participation } \\
\text { factor }\end{array}$} & X-earthquake & 98.1 & 98.4 & 98.3 & \multirow{2}{*}{$\geq 90 \%$} \\
\hline & Y-earthquake & 98.3 & 98.0 & 98.3 & \\
\hline
\end{tabular}




\subsection{Pushover analysis}

Pushover analysis subjected to rare earthquake influence is carried out on the structure. Based on ATC-40 and FEMA-273, Capacity Spectrum Method (CSM) is used to evaluate the seismic behavior[4]. In the program, three different kinds of horizontal load modes are introduced to examine the structure actions. Modal distribution pattern, constant acceleration distribution pattern and the triangle wind distribution pattern are produced on the building separately. When pushover finishes, plastic hinges appear on the structure. By this way, weak regions of the building are found and investigated.

As in Fig.3-6, plastic hinges distribution are given under modal distribution pattern and constant acceleration distribution pattern. Comparative study shows wind distribution pattern load produce less influence on the structure. Weak regions or certain frame members can be examined for further design work.
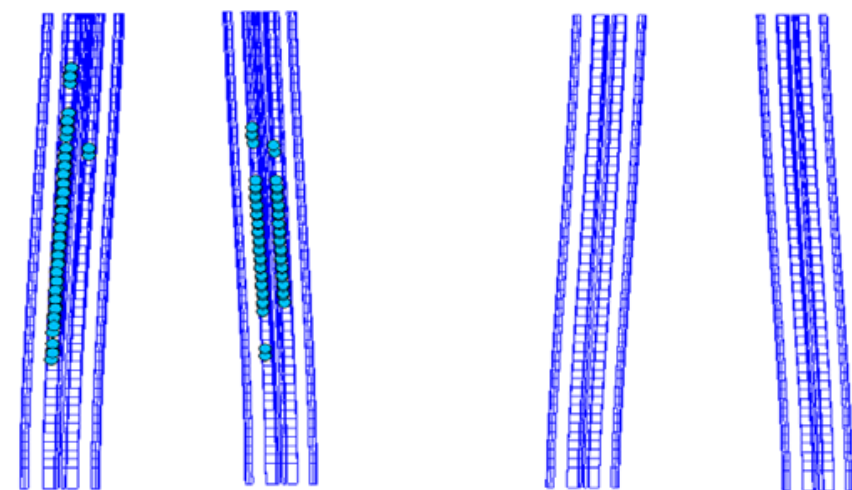

(a) positive

(a) opposite

(b) positive

(b) opposite

Fig.3 Walls at vertical elevator cores and periphery shear walls (Note: a: modal distribution pattern; b: acceleration distribution pattern)

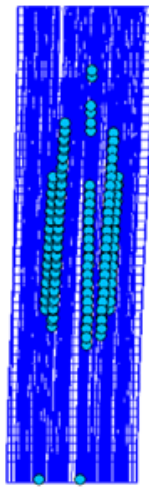

(a) positive



(a) opposite

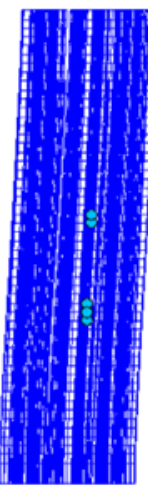

(b) positive

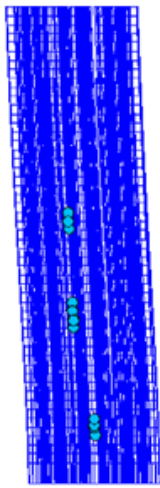

(b) opposite

Fig. 4 Walls along the building periphery

(Note: a: modal distribution pattern; b: acceleration distribution pattern)



(a)

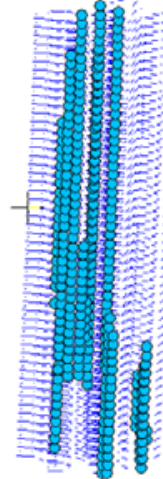

(b)

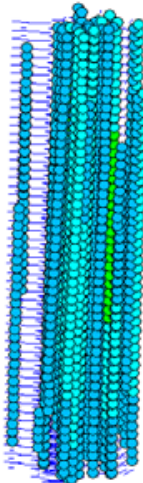

(a)

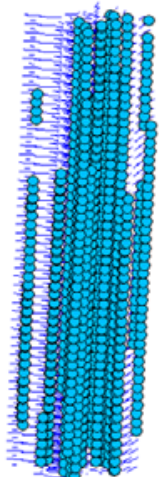

(b)

Fig.5 Coupling beam

Fig.6 Frame beam

(Note: a: modal distribution pattern; b: acceleration distribution pattern) 
The capacity curves under all load conditions are smooth without mutated section[5-6]. The capacity spectrum has a point of intersection with earthquake demand spectrum. The strength and stiffness of structure in $\mathrm{X}$ direction and $\mathrm{Y}$ direction is consistent.

The elastic-plastic inter story displacement angle is less than 1/120 which is within the elastic-plastic displacement angle limit (1/120). The maximum inter-story displacement appears in 24-30 floors in $\mathrm{X}$ direction. The maximum inter-story displacement appears in 25-36 floors in $\mathrm{Y}$ direction.

Plastic hinge development sequence is studied. Bending plastic hinges are appeared first in beams. Then, hinges gradually extend toward higher floors from the lower floors. To the rare earthquake performance, shear walls at the bottom within the core tube emerge slight plastic hinge. While all wall appear no shear hinge[7].

\section{Seismic fortifications}

Some fortification measurements are included to enhance the ductile performance of the building based on the analytical evaluation. Axial compression ratio is strictly limited within 0.5 in order to enhance the ductility of bottom walls in bottom 6 floors. Horizontal and vertical reinforced bars with minimum steel ratio of $0.4 \%$ are distributed in these bottom walls. While a minimum steel ratio of $0.35 \%$ bars are distributed in walls of upper floors. Based on pushover analysis, a minimum steel ratio of $1.2 \%$ bars are distributed in weak regions evaluated by rare earthquake analysis. Those beam members which suffer severe plastic deformation are especially enhanced by way of increasing the section or steel bar ratio[8]. Thus, those key beams can achieve higher capacity and avoid severe damage. Additionally, top five floors are also enhanced considering the seismic response is more severe than middle floors.

\section{Summary}

Three different numerical models by finite element packages are established to analyze the behavior of the structure. Results show the structure can reach the seismic design requirements. Envelope results of three procedures are used in construction drawings. Under frequently earthquake influence, all members are stay elastic. When under local fortification intensity influence, all lateral resist members remain elastic while some beams yield and display ductile damage. Pushover results show a small number of wall member damage. The building can be considered slightly damaged. Based on rare earthquake influence analysis, effective fortification measurements are included to enhance the ductile performance of the building even under rare earthquake influences.

\section{Acknowledgements}

This work was supported by the Key Scientific Research Projects of Colleges and Universities in Henan Province (15B413002,16A120015), and by the Young teachers promotion program of Huang huai University(201512708).

\section{References}

[1] Wu Lili, Xing Ruijiao, Ma Yongjun, et al. Experimental study on shear behavior of steel plate-concrete composite slabs with small shear span ratio [J]. Engineering Mechanics, 2014, 31(12): 112-118.

[2] Jiang Huanjun, Liu Qizhou. State-of-the-art of the research advances on resilient shear walls [J]. Journal of Vibration and Shock, 2015, 34(7): 51-58. 
[3] Jones P, Zareian F. Seismic response of a 40-storey buckling-restrained braced frame designed for the Los Angeles region [J]. The Structural Design of Tall and Special Buildings, 2013, 22(3): 291-299.

[4]Guo Lanhui, Ma Xinbo, Zhang Sumei. Experimental study on connection details of composite steel plate shear wall connected with frame beams [J]. Engineering Mechanics, 2012, 29(8): 150-158.

[5]Nie Jianguo, Wu Lili, Fan Jiansheng, et al. Preliminary study of channel steel-concrete composite beam and application [J]. China Civil Engineering Journal, 2008,41(11): 78-85.

[6]Liang Q Q, Uy B, Wright H D, et al. Local buckling of steel plates in double skin composite panels under biaxial compression and shear [J]. Journal of Structural Engineering, 2004, 130(3): 443-451.

[7]Sun Jianchao, Xu Peifu, Xiao Congzhen, et al. Experimental study on shear behavior of steel plate-concrete composite wall [J]. Building Structure,2008, 38(6): 1-5.

[8]Qu Z, Wada A, Motoyui S, et al. Pin-supported walls for enhancing the seismic performance of building structures [J]. Earthquake Engineering \& Structural Dynamics, 2012,41(14): 2075-2091. 